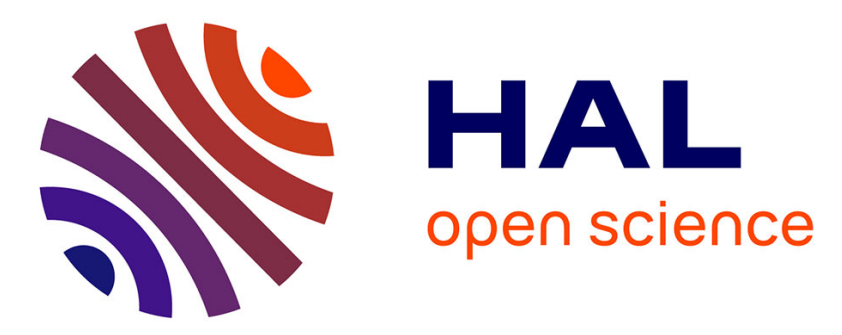

\title{
A Species Specific Investigation Into Sheep and Goat Husbandry During the Early European Neolithic
}

Rosalind Gillis, Jane S Gaastra, Marc Vander Linden, J.-D. Vigne

\section{To cite this version:}

Rosalind Gillis, Jane S Gaastra, Marc Vander Linden, J.-D. Vigne. A Species Specific Investigation Into Sheep and Goat Husbandry During the Early European Neolithic. Environmental Archaeology, In press, 10.1080/14614103.2019.1615214 . mnhn-02399684

\section{HAL Id: mnhn-02399684}

\section{https://hal-mnhn.archives-ouvertes.fr/mnhn-02399684}

Submitted on 15 Dec 2019

HAL is a multi-disciplinary open access archive for the deposit and dissemination of scientific research documents, whether they are published or not. The documents may come from teaching and research institutions in France or abroad, or from public or private research centers.
L'archive ouverte pluridisciplinaire HAL, est destinée au dépôt et à la diffusion de documents scientifiques de niveau recherche, publiés ou non, émanant des établissements d'enseignement et de recherche français ou étrangers, des laboratoires publics ou privés. 


\section{Environmental Archaeology}

The Journal of Human Palaeoecology

\section{A Species Specific Investigation Into Sheep and Goat Husbandry During the Early European Neolithic}

\section{Rosalind E. Gillis, Jane S. Gaastra, Marc Vander Linden \& Jean-Denis Vigne}

To cite this article: Rosalind E. Gillis, Jane S. Gaastra, Marc Vander Linden \& Jean-Denis Vigne (2019): A Species Specific Investigation Into Sheep and Goat Husbandry During the Early European Neolithic, Environmental Archaeology, DOI: 10.1080/14614103.2019.1615214

To link to this article: https://doi.org/10.1080/14614103.2019.1615214

View supplementary material $\sqsubset$

曲 Published online: 25 May 2019.

Submit your article to this journal ש

LII Article views: 30

View Crossmark data $\nearrow$ 


\title{
A Species Specific Investigation Into Sheep and Goat Husbandry During the Early European Neolithic
}

\author{
Rosalind E. Gillis (D) ${ }^{\mathrm{a}, \mathrm{d}}$, Jane S. Gaastra (D) ${ }^{\mathrm{b}}$, Marc Vander Linden (iD) ${ }^{\mathrm{c}}$ and Jean-Denis Vigne (D) ${ }^{\mathrm{d}}$ \\ ${ }^{a}$ Institut für Ur- und Frühgeschichte/Graduate School, Christian-Albrechts-Universität, Kiel, Germany; ${ }^{b}$ Institute of Archaeology, University \\ College London, London, UK; ' Department of Archaeology, University of Cambridge, Cambridge, UK; ${ }^{\mathrm{d}} \mathrm{CNRS}$ - Muséum National d'Histoire \\ Naturelle, Archéozoologie, Archéobotanique: Sociétés, Pratiques et Environnement, Paris, France
}

ABSTRACT

Archaeozoological assemblages are important sources of information on past management strategies, which are influenced by cultural practices as well as the physical geography and climate. Sheep, goat and cattle arrived in Europe with early Neolithic migrants. Their distribution is believed to have been mainly influenced by the geography of European regions although individual species may have held symbolic importance for specific Neolithic cultures. Domesticated animal mortality data derived from dental eruption, wear and replacement can provide insights into slaughter management and consequently animal husbandry practices. Previous studies have focused on caprines (sheep and goat) collectively as a results of their morphological similarity. Here we present a species specific study of sheep and goat mortality data from early European and Anatolian Neolithic contexts using correspondence analysis. The results show that for sheep there were significant differences in slaughter management practices between regions, cultures and site types whereas for goats there was none. This initial examination into sheep and goat husbandry during the Neolithic suggests that cultural practices as well as regional geography played an important role in shaping management practices.
ARTICLE HISTORY

Received 5 April 2018

Revised 3 April 2019

Accepted 26 April 2019

\section{KEYWORDS}

Sheep (Ovis aries); goats (Capra hircus); Neolithic; Europe; mortality data; correspondence analysis

\section{Introduction}

Sheep (Ovis aries) and goat (Capra hircus) are an important component of modern livestock systems, producing renewable products such as milk, hair/ wool, manure and traction as well as final products such as meat, skin, horn and bone. Their osteological morphology is very similar but they, however, have different physiological and productive capacities (Prendergast et al. 2018; Gillis, Chaix, and Vigne 2011; Balasse and Ambrose 2005; Halstead, Collins, and Isaakidou 2002; Haenlein 2001). Sheep are natural grazers, with short lactation lengths that produce milk with a high fat content, ideal for cheese making. In comparison, goats are browsers and can exist in areas of rough grazing to such a degree that they have been used deliberately to remove unwanted vegetation in some areas. They have a long lactation length earning them the synonym 'the poor man's cow' (Haenlein 2007). Both species can survive in arid regions with infrequent water sources. Present day husbandry systems for these species vary greatly between southern and northern Europe. In the Mediterranean region, there is a focus towards systems that produce milk, lambs ( $<12$ months) and wool. In the Balkans, transhumance with a focus on milk production was widely practised by stockherders who range from Northern Greece to Croatia and Serbia (Ryder 1999). In central and northern Europe, sheep were traditionally used for wool and meat production. Specialised milk breeds for cheese production have been developed during the last century from traditional breeds with the capacity for good milk production such as Lacaune and East Friesian sheep and the Saanen Goat.

Direct morphological evidence for sheep and goat domestication has been identified at Pre-Pottery Neolithic (PPN) sites in the northern Levant and Zagros regions respectively, dating to the 9th millennium cal BC (Vigne et al. 2011; Peters et al. 1999; Zeder 1999). They were introduced into Europe by early Neolithic farmers, which is evident by the absence of a putative wild ancestor (Poplin 1979; Uerpmann 1987). From this point onwards, caprines formed an important cornerstone of prehistoric subsistence practices (Helmer, Gourichon, and Vila 2007; Arbuckle et al. 2014). They were the predominate species for Early Neolithic settlements of southern Europe; this is in part a reflection of their success in drier climates in comparison to cattle (Manning et al. 2013). Neolithic cultures spread or were adopted by local hunter-gatherer groups along two main routes: following the northern Mediterranean seaboard to the west and major European

CONTACT Rosalind E. Gillis roze.gillis@gmail.com Institut für Ur- und Frühgeschichte, Christian-Albrechts-Universität, Johanna-Mestorf-Straße 2-6, Kiel D-24098, Germany; CNRS - Muséum National d'Histoire Naturelle, Archéozoologie, Archéobotanique: Sociétés, Pratiques et Environnement, (UMR 7209), CP56, 55 rue Buffon, Paris F-75005, France

(1) Supplemental data for this article can be accessed at https://doi.org/10.1080/14614103.2019.1615214. 
rivers to the north. Along the Mediterranean seaboard, caprines dominated the Impressa and Cardial culture assemblages with some exceptions in south-eastern Italy (Rowley-Conwy et al. 2013). As Neolithic groups spread northwards into central and eastern Europe via the Balkans the proportions of sheep and goats kept at sites became more variable with an overall shift through time towards a greater reliance on the herding of cattle and pigs (Orton, Gaastra, and Linden 2016). This shift in focus towards cattle continued as the Neolithic way of life spread further into the north. Cattle were the predominate animal of the early Neolithic cultures, such as the Linearbandkeramik of central and northern Europe. In some areas, such as Southern Bavaria, caprines were more numerous than cattle (Lüning 2000). Moreover, Marciniak (2013) proposed that caprines may have used as the meat source with cattle being used for ritual consumption in LBK sites in southern Poland.

Individual domesticated species have different productive capacities, which may have been exploited by herdsmen since their domestication. Understanding the individual roles of sheep and goats since their domestication has been hampered by poor identification due to the similarity in their osteological morphology (Boessneck, Müller, and Teichert 1964). In the last twenty years, there has been methodological advances in identifying sheep and goats using dental morphology (Gillis, Chaix, and Vigne 2011; Zeder and Pilaar 2010; Balasse and Ambrose 2005; Halstead, Collins, and Isaakidou 2002). Animal teeth are an excellent source of information about past slaughter management and consequently husbandry practices. Here we present an analysis of species specific mortality profiles to investigate, compare and characterise sheep and goat husbandry practices during the early phases of the European Neolithic (7th to 5th millennium cal BC).

\section{Material and Methods}

Caprine age-at-death determination using eruption and replacement of dental remains was first established by Ewbank et al. (1964). This methods was followed by age determination methods using occlusal dental wear stages based on the study of modern Turkish sheep (Payne 1973, 1987) and observations of caprines from English Iron Age sites Grant (1982). Additional methods using the crown height and width were introduced by Ducos (1968) and re-examined by Gaastra (2016), the former was integrated into Payne's original age classes by Helmer, Gourichon, and Vila (2007).

Species specific age-at-death methodologies specifically for eruption and wear stage have been devised by Silver (1963; based 'improved breeds' and hill sheep '1790'), Weinreb and Sharav (1964), Payne (1973, 1987; Turkish sheep) and Jones (2006; based on observations of modern hill sheep). Goat age-at- death schemes are reported by Silver (1963), Bullock and Rackham (1982; based on feral Scottish goats) and Deniz and Payne (1982; Turkish goats). There are slight differences between species in terms of eruption of the deciduous premolars (erupt later in goats), premolars and molars (erupt earlier in goats; Gillis (2012)). Many of the studies concerning goats were dominated with male goats, whose teeth have been observed to have erupted earlier than in females (Mellado et al. 2007).

We included isolated teeth in the final count (deciduous premolar 4, premolar 4, molars 1-3), because of the fragmented nature of Early Neolithic remains and the infrequent recovery of complete or large portions of mandibles. First and second molars can often be mistakenly identified as each other, to prevent this we took measurements (height and distance anterior/posterior) of known M1 and M2s and compared with loose M1and M2s. Isolated teeth found to belong to several age classes were divided between them according to the respective time length of the age classes according to Payne (1973).

Age-at-death determinations were made using Payne (1973), RG and JSG additional used Ducos (1968) and Gaastra (2016) respectively to refine the age of adults using crown-height indexes. Those sites studied by RG and JSG, sheep and goat were distinguished using methodologies established by (Helmer 2000; Halstead, Collins, and Isaakidou 2002; Balasse and Ambrose 2005; Zeder and Pilaar 2010; Gillis, Chaix, and Vigne 2011; Boessneck, Müller, and Teichert 1964).

\section{The Dataset}

We collected mortality data based on dental remains from 35 sheep profiles from 25 sites and 17 goat profiles from 18 sites (Figure 1; Table 1). RG studied and differentiated the caprine remains from 17 sites (La Draga (LAD), Font Juvenal (FON), Trasano (TRA), Füzseabony-Gubakút (FUZ), Apc-Berekalja (APC), Polgár-Piócási-dűlő (PIO), Polgár-Ferenci-hát (FER), Ludwinowo (LUD), Mold (MOL), TěšeticeKyjovice (TES), Dillingen-Steinheim (WIK), Herxheim (HEX) and Bischoffsheim (BIS)). While JSG studied and differentiated the caprine remains from 3 sites (Spila Nakovana (SPI), Kneževi Vinograd (KNE), Belišće (BEL)). The remaining sties were collected from published sources detailed in SDATA1. The sites are representative of early Neolithic cultures from Anatolia, the Balkans, north-western Mediterranean, central Europe and northern European plain. Sites/phases with a total less than 6 teeth per species were removed. On average the total sample size per site/site phase was 33 for sheep and 24.5 for goats.

The sites Erbaba Höyük (ERB, central Anatolia (Arbuckle 2008)) and Ulucak Höyük (ULU, western 


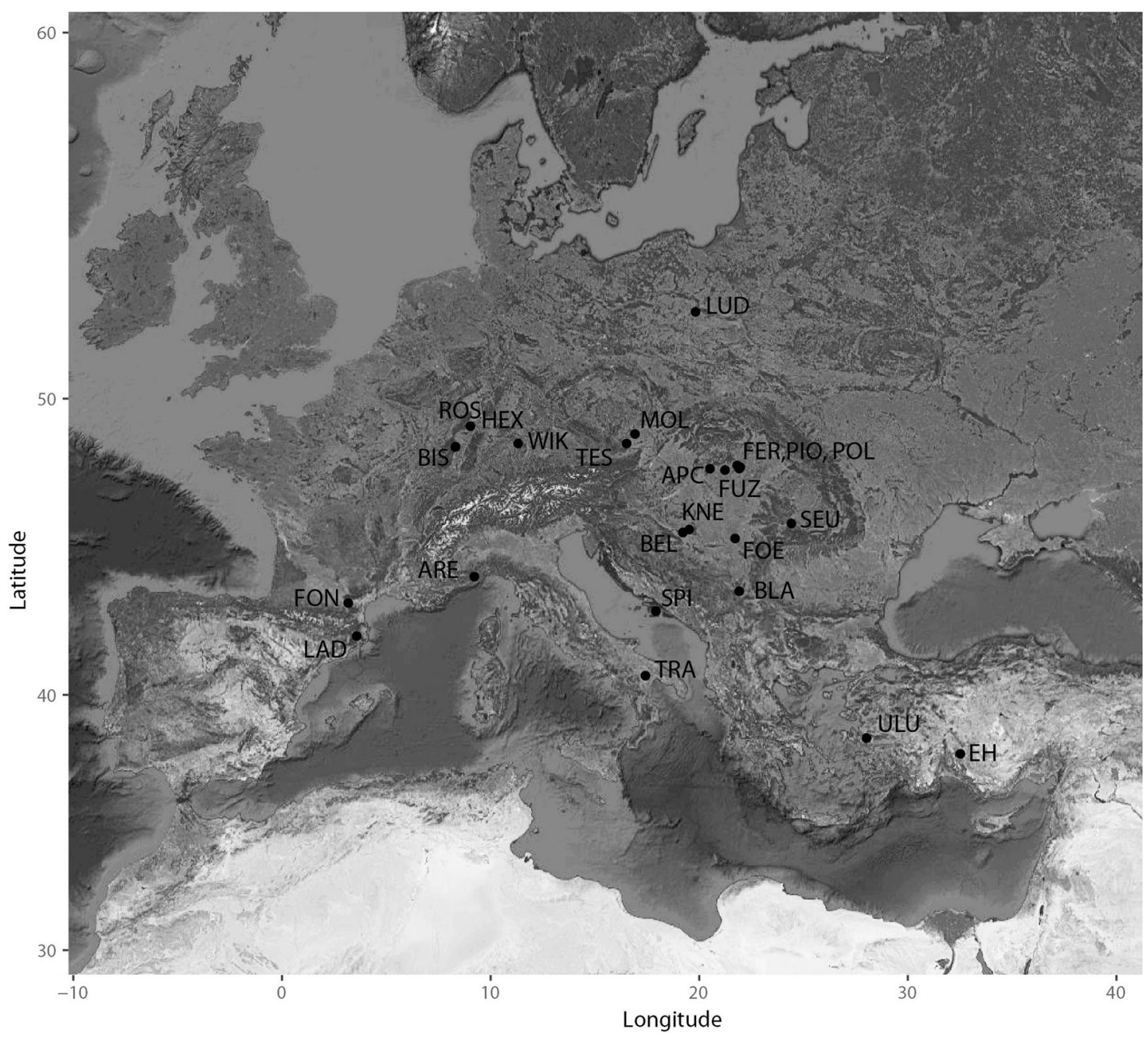

Figure 1. Map of site locations: Erbaba Höyük (ERB), Ulucak Höyük (ULU), Spila Nakovana (SPI), Belišće (BEL), Blagotin (BLA), SeuşaCararea Morii (SEU), Foeni-Salaş (FOS), Polgár 10 (POL), Kneževi Vinograd (KNE), Font Juvenal (FON), La Draga (LAD), Trasano (TRA), Arene Candide (ARE), Füzseabony-Gubakút (FUZ), Apc-Berekalja (APC), Polgár-Piócási-dűlő (PIO), Polgár-Ferenci-hát (FER), Ludwinowo (LUD), Mold (MOL), Těšetice-Kyjovice (TES), Dillingen-Steinheim (WIK), Herxheim (HEX) and Bischoffsheim (BIS). Map was produced using ggmaps (Kahle and Wickham 2013), satellite base map from Google maps Imagery @ Terrametrics.

Anatolia (Çakirlar 2012)) are contemporary with prepottery to middle Neolithic sites in Greece (67005700 cal BC). The caprine remains from Ulucak Höyük have recently been the focus of a multi-proxy biomolecular examination (Pilaar-Birch et al. 2018), in particular using collagen fingerprinting to identify sheep and goat from a sample of 15 mandibles (ZooMS).

Sites from the Balkans are representative of the initial inland spread of the Neolithic. These are attributed to the Starčevo-Körös-Criş (SKC) cultural complex (c.61/6000-55/5400 cal BC) and include the open-air settlements of BEL (Serbia, Gaastra unpub.), Blagotin (BLA, (Greenfield and Jongsma Greenfield 2014)), Seusa-Cararea Morii (SEU, Romania, (El Susi 2000)), Foeni-Salas (FOE, Romania, (Greenfield and Jongsma Greenfield 2014)). The early Neolithic openair settlement of KNE (Gaastra (2016)) dates to c.6015-5846 cal BC represents a local early Neolithic cultural variant of Starčevo-Körös-Criş (SKC) cultural complex, which is currently not well understood.
Adriatic sites are the maritime cave site of SPI (Croatia, Gaastra unpub.) and open air site of TRA (Italy, Gillis 2012), and are associated with the impresso/impressa culture (c.6000-5500 cal BC). Franco-Iberian sites are represented by cardial sites (FON (France, Gillis 2012)); LAD (Spain, Gillis 2012); ARE (Italy, (Rowley-Conwy 1997)) which date from 6400 to $4800 \mathrm{BC}$ cal. All the sites are open-air settlements apart from FON and ARE Candide, which are cave/rock shelters. Given the similarities in pottery styles between the impresso/ impressa and cardial culture, these sites collectively are classed as the impressa-cardial ware complex (ICW).

Polgar 10 (POL) represents the Körös culture apart of the Starčevo-Körös-Criş (SKC) cultural complex in the Hungarian Plain (central European region) (Brighton, Dobney, and Chapman 2010). Also within this region are four sites that represented the Transdanubia (TLP; APC) and Alföld Linear Pottery (ALP; FUZ, PIO and FER) cultures. These date to the 
Table 1. Details of species identified, culture, region, climate and site type for studied sites.

\begin{tabular}{|c|c|c|c|c|c|c|c|}
\hline Site & Code & Ovis/ Capra & Culture & Region & Climate & Site type & Citation \\
\hline Ulucak Höyük & ULUVI-IV & 0 & PPN/NA & Anatolia & Csa & open & Çakirlar 2012 \\
\hline Erbaba Höyük & ERB1-3 & $\mathrm{O} / \mathrm{C}$ & LNA & Anatolia & Csa & open & Arbuckle 2008 \\
\hline Belisce & BEL & 0 & SKC & Balkans & Dfb & open & Gaastra unpublished \\
\hline Knezevi Vinograd & KNE & $\mathrm{O} / \mathrm{C}$ & SKC & Balkans & Dfb & open & Gaastra unpublished \\
\hline Foeni-Salas & FOE & 0 & SKC & Balkans & Dfa & open & Greenfield and Jongsma Greenfield 2014 \\
\hline Seusa-Cararea Morii & SEU & 0 & SKC & Balkans & Dfc & open & El Susi 2000 \\
\hline Blagotin & BLA & 0 & SKC & Balkans & $\mathrm{Csb}$ & open & Greenfield and Jongsma Greenfield 2014 \\
\hline Mold & MOL & $\mathrm{O} / \mathrm{C}$ & LBK & Central & Dfb & open & Gillis unpublished \\
\hline Těšetice-Kyjovice & TES & 0 & LBK & Central & Dfb & open & Gillis unpublished \\
\hline Polgár 10 & POL & 0 & SKC & Central & Dfb & open & Brighton, Dobney, and Chapman 2000 \\
\hline Polgár-Piócási-Dűlő & $\mathrm{PIO}$ & 0 & LBK & Central & Dfb & open & Gillis unpublished \\
\hline Apc-Berekalja & APC & 0 & LBK & Central & Dfb & open & Gillis unpublished \\
\hline Polgár-Ferenci-Hát & FER & $\mathrm{O} / \mathrm{C}$ & LBK & Central & Dfb & open & Gillis unpublished \\
\hline Füzseabony-Gubakút & FUZ & $\mathrm{O} / \mathrm{C}$ & LBK & Central & Dfb & open & Gillis unpublished \\
\hline Ludwinowo & LUD & $\mathrm{O} / \mathrm{C}$ & LBK & NW Plain & Dfb & open & Gillis unpublished \\
\hline Bischoffsheim & $\mathrm{BIS}$ & $\mathrm{O} / \mathrm{C}$ & LBK & NW Plain & $\mathrm{Cfb}$ & open & Gillis submitted \\
\hline Rosheim & ROS & $\mathrm{O} / \mathrm{C}$ & LBK & NW Plain & $\mathrm{Cfb}$ & open & Gillis unpublished \\
\hline Herxheim & HEX & $\mathrm{O} / \mathrm{C}$ & LBK & NW Plain & $\mathrm{Cfb}$ & open & Gillis in press \\
\hline Dillingen-Steinheim & WIK & $\mathrm{O} / \mathrm{C}$ & LBK & NW Plain & $\mathrm{Cfb}$ & open & Gillis unpublished \\
\hline Font Juvenal & FON & $\mathrm{O} / \mathrm{C}$ & ICW & Franco-Iberian & $\mathrm{Cfb}$ & cave/rockshelter & Gillis 2012 \\
\hline Arene Candide & ARE & 0 & ICW & Franco-lberian & Csa & cave/rockshelter & Rowley-Conwy 1997 \\
\hline La Draga & LAD & $\mathrm{O} / \mathrm{C}$ & ICW & Franco-Iberian & $\mathrm{Cfb}$ & open & Gillis 2012 \\
\hline Spila Nakovana & SPI & 0 & ICW & Adriatic & Dfb & cave/rockshelter & Gaastra unpublished \\
\hline Trasano & TRA & $\mathrm{O} / \mathrm{C}$ & ICW & Adriatic & Csa & open & Gillis 2012 \\
\hline
\end{tabular}

Hungarian middle Neolithic (5600-4600 cal. BC) and follow the Starčevo (Transdanubia) and the Körös (Hungarian Plain) cultures. The TLP is believed to be the progenitor of the Linearbandkeramik cultural phenomenon while the ALP lies east of the Danube and differs in style although it has many similarities with TLP/LBK phenomenon (Whittle et al. 2013). Previous analysis of cattle from these sites together with remains from LBK sites have shown there is little difference in terms of husbandry practices (Gillis et al. 2017). Therefore we have amalgamated the data from these sites with those from LBK sites in central and north western European regions. If there is a difference between management strategies of these cultural groups then it will be apparent in the correspondence analysis.

Other sites from the central region of Europe are MOL (Austria, Gillis unpub.), TES (Bohemia, Gillis unpub) and date to the LBK culture (5500-4900 BC). Other LBK sites are located within the NW European plain region. These are LUD (Poland, Gillis unpub), WIK (Germany, Gillis unpub), HEX (Germany, Gillis unpub) and BIS (France, Gillis unpub) and they all date from 5500 to $4900 \mathrm{cal}$. BC.

Climate reference codes were given to each site based on the revised Köppen's classification (Peel, Finlayson, and McMahon 2007) for their location. These zones are one of five climate types: Temperate without dry season and hot summer (Cfa) and warm summer (Cfb); Temperate dry summer with hot summer (Csa) and warm summer (Csb); Cold without dry summer with warm summer (Dfb). As several climatic oscillations have been recorded during the Early Neolithic time periods under consideration in this study (e.g. Fiorentino et al. (2013); Feeser et al. (2016)), these reference codes are incorporated only as an approximate representation for the climatic zones of sites used in this study.

\section{Statistical Methodology}

Common methods to compare mortality data, such as, $\mathrm{Chi}^{2}$ (Helmer et al. 2005) and Mann-Whitney U-test (Greenfield and Arnold 2015), do not adequately assess the high level of sampling uncertainty in age-at-death data due to numerous factors, such as differential preservation and recovery, and particularly small sample sizes associated with early Neolithic assemblages. Correspondence analysis (CA) has been used as an alternative to these methods by several researchers (e.g. Gillis et al. 2017; Helmer, Gourichon, and Vila 2007). CA is a descriptive statistical analysis that can be used to visualise data and elucidate the 'correspondence' between datasets to generate hypotheses rather than testing the data using statistical inferences. This analysis produces data that plots two clouds of data; rows (number of teeth within 7 age classes for site) and columns (7 age classes) (Benzécri 1973). Thus it can, on the one hand, clearly illustrate the age classes that are the most common within a dataset, and on the other, elucidate relationships between sites and their association with particularly age classes.

Gerbault et al. (2016) proposed to use Dirichlet distribution to account for the sampling uncertainties within each age class for a given age-at-death profile. This distribution is the conjugate prior of a multinomial distribution within a Bayesian framework analysis. In this case, the Dirichlet distribution, with an appropriate prior (here Jeffrey's prior of 0.5 ), is used to generate random deviates of the population relative frequencies based on a given age-at-death profile (number of simulations here is 5000). This is carried 
out using the 'rdirichlet' function from the $\mathrm{R}$ package LaplacesDemon (V16.0.1, (Statisticat 2016)). Each Dirichlet deviate is then multiplied by the sample total observed in the original age-at-death profile in order to obtain a comparable simulated dataset. These deviates can be analysed using CA, creating data point clouds around the original data point thus providing an indication of the potential distribution of the sample from each site. Therefore where a data cloud is widely dispersed may suggests issues within the sample, such as small sample size, and where the data cloud is small may suggest that the original age-at-death profile is a true reflection of mortality at that site.

The CA coordinates represent the distances between rows and columns respectively. To test trends visualised within the CA biplots, we used several non-parametric statistical tests, such as Mann-Whitney and ANOSIM, on the mean value of CA F1 and F2 coordinates (including deviates) respectively generated for each site using culture, climate, site type and region as grouping factors. The ANOSIM (analysis of similarities) is a non-parametric test used in ecology (vegan R package (Oksanen et al. 2017)). Although similar to the ANOVA-like dissimilarities test, ANOSIM uses a ranked dissimilarity matrix. The test statistic $R$ varies within the range $[-1,1]$ when $R$ is close to 1 suggests dissimilarity between groups, whereas when $R$ is close to zero suggests even distribution of high and low ranks within and between groups and when it is below zero, it suggests dissimilarity is greater within groups than between groups. All analyses and biplots were produced using the free platform R programme (V3.03.3; R Team 2017) using R studio (R Studio Team 2016). The $\mathrm{R}$ packages used were: ggplot2 (V1, (Wickham 2009)), ca (Nenadic and Greenacre 2007), LaplacesDemon (V16.0.1, (Statisticat 2016)) and MASS (V7.3-37, (Venables and Ripley 2002)).

\section{Results}

We carried out 5000 simulations for each site sheep/ goat profile following the Gerbault et al. (2016) methodology for caprines. Correspondence analysis (CA) was then carried out on for the sheep and goat datasets. The age class $0-2 \mathrm{M}$ dominates both $\mathrm{CA}$ plots due to the low representation in this age class, which has been seen in other CA analysis of caprines (Helmer, Gourichon, and Vila 2007).

For sheep (Figure 2a), the CA had a global inertia of 0.71 with the $\mathrm{F} 1$ and $\mathrm{F} 2$ axis explaining $30 \%$ and $21.9 \%$ respectively of the total variation. Overall the CA analysis for sheep is explained by the opposition on the F1 axis between age classes 6-12 months and 2-4 years (-ve coordinates) and 2-6 months (+ve coordinates) as well as the opposition between age classes 6-12 months (-ve coordinates) and 2-4 years (+ve coordinates) on the F2 axis. Sites associated with SKC and ICW cultures are located between 6-12 months and 2-4 months with several ICW cave sites more
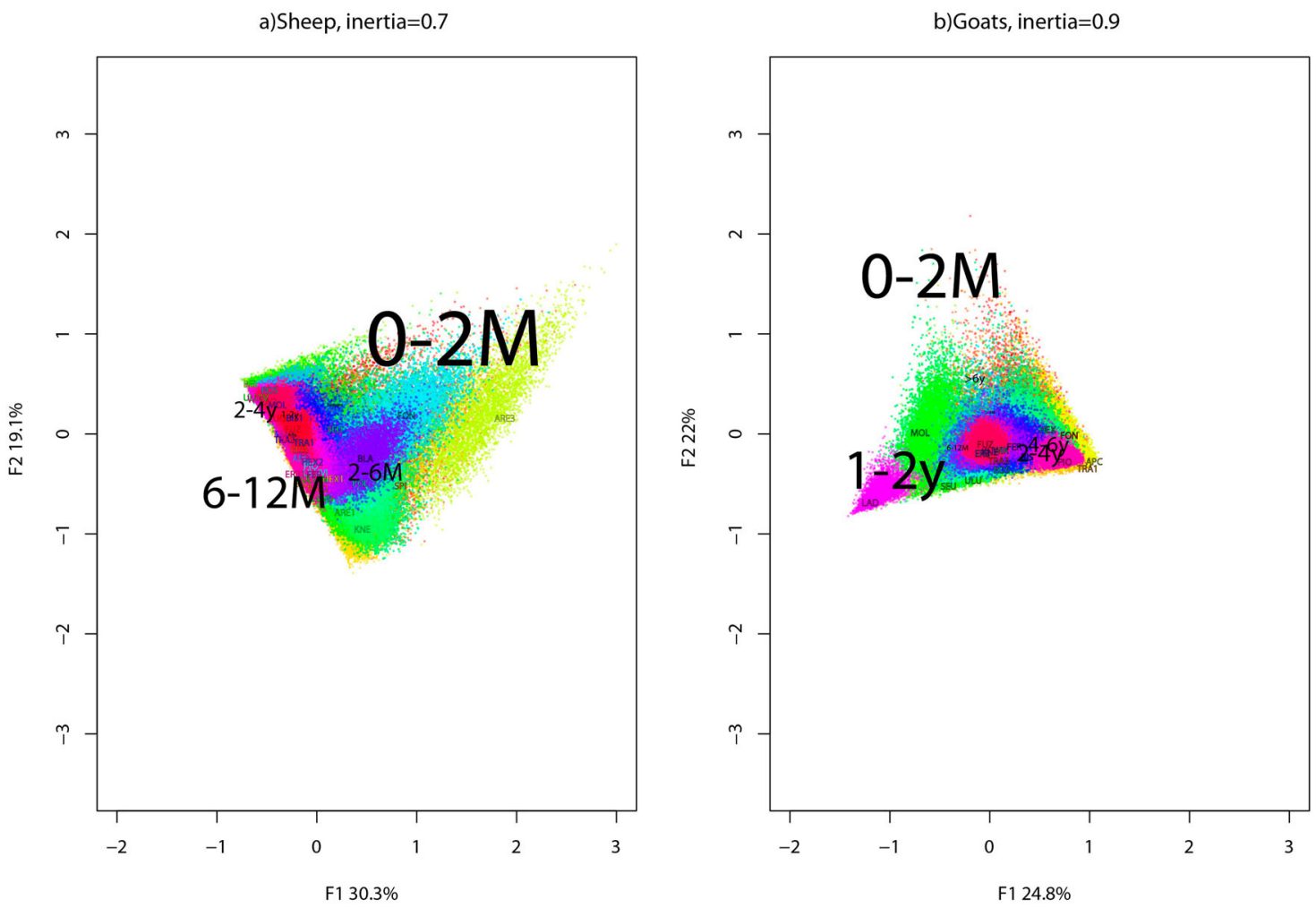

Figure 2. (a) Sheep correspondence analysis biplots; (b) Goat correspondence analysis biplots, with 5000 Dirichlet simulations for each site. The colour of points refers to individual sites and the site code are labelled with the corresponding colour. The size of the age class lettering reflects the contribution of each age class to the axes. 
closely associated with age class $2-4$ months (ARE, FON). In comparison LBK sites (MOL, WIK, BIS1/3, HEX, LUD and ROS) are more closely associated with adult age classes. There are exceptions; for example, Trasano (TRA) and La Draga (LAD), both ICW sites are more closely associated with age classes 2-4 and 4-6 years. Furthermore, Anatolian (ERB and ULU) sites and those from central Europe (TES, PIO, FER and APC) lie between 6-12 months and 4-6 years.

The global inertia for the goats CA (Figure $2 \mathrm{~b}$ ) was 0.91 where F1 and F2 explained 24.9 and $21.9 \%$ of the variation respectively. The CA goat biplot was structured on the F1 axis between age classes 1-2yrs (-ve coordinates) versus $2-4$ yrs and 4-6yrs (+ve coordinates). There are some indication of differences between sites of the same region or similar regions, such as the opposition between LAD and FON, with the latter site situated close to age class 2-4/4-6 years. This can also be seen between FUZ, PIO and APC where the first site is associated with age class 6-12 months while the remaining two are more closely associated with 2-4/4-6 year. Other LBK sites from central and north-western plain regions, such as WIK, BIS, HEX1 and MOL are located between age classes 6-12 months and 2-4/4-6 years.

We calculated the mean F1 and F2 coordinates for sheep and goat from each site (Figure 3a-g, using F1 coordinates). We used these to produce boxplots using the four grouping factors (culture, climate, site type and region). For sheep, we found a significant difference between site attributed to SKC and LBK (Mann-Whitney $p=0.01$ ) and site types (Mann-Whitney $p>0.05$ ). We can observe that sites with ICW phases have a similar distribution to SKC sites. This appears to be reflected in $\mathrm{F} 1$ mean coordinates grouped by regions, where sites from the Balkans and FrancoIberian peninsula have more negative coordinates than other regions. For goats, there is little difference between coordinates for cultural phases, regions, climate type or even site types.

To further examine similarities and differences between groups, we carried out an analysis of similarity (ANOSIM, permutations $=999)$ on the mean CA F1 and F2 coordinates using culture, climate, site type and region as grouping factors (Table 2). For goats, no significance was found for any of the categories nor was there any correlation between coordinates and longitude and latitude. For sheep, the ANOSIM was significant for culture, site type and region. The $\mathrm{R}$ statistic is low but suggests that there is dissimilarity between variables within each of the grouping factors: culture, site type and region.

Overall, the results suggest that sheep management strategies differed between cultural groups within specific regions, i.e. stockherders of the SKC sites within the Balkans managed their sheep differently to LBK ones from central Europe and NW plain. This is suggested by the tendency of SKC sites towards -ve F1 coordinates (Figure 3a). These coordinates are associated with younger age classes (0-2 months, 2-6 months). However, there is a wide distribution of CA F1 mean coordinates for ICW sites (Figure 3a), which is also seen within the Franco-Iberian region. This suggests that within this cultural group, particularly within the Franco-Iberian region, that sheep management strategies were diverse and stockherders adapted sites in relation to specific practices. Cave sites within this dataset have a tendency towards negative coordinates, suggesting that they were used as seasonal camps for birthing stations or dairies within a short-ranged pastoral system (Vigne and Helmer 1999).

\section{Discussion}

Sheep and goats are often herded together but have different productive capacities, such as milk quantity and quality, as well as physiological differences. These are and have been exploited by pastoralists and stock herders around the world. However, it is not clear whether these differences were recognised and utilised by stockherders at the beginning of the Neolithic. Ethnological observations, particularly of sheep for the Middle East and Anatolia, have been used to develop a framework to interpret/model age-at-death mortality profiles (Payne 1973; Redding 1981; Halstead 1998; Vigne and Helmer 2007). Here we were considering the effect of species identification and age-at-death methodologies on sheep and goat mortality analysis. We discuss the results in light of these potential biases and use ethnographic studies of European sheep and goats as a framework to interpret early Neolithic husbandry practices.

\section{Methodological Issues}

We previously highlighted that the use of age-at-death methodology based on sheep could skew age-at-death determination. Comparison between species specific age determination methodologies has shown there is a slight differences between sheep and goats dental eruption (Gillis 2012). The molars on average erupt 1-2 months later in goats than in sheep whereas the deciduous premolars erupted later in sheep. There may also be differences between sexes in terms of eruption and wear stages with males having increased dental wear (Deniz and Payne 1982; Mellado et al. 2007). These differences in eruption and wear stages can have an impact on mortality analysis. For example, age class 6-12 months, 1-2 years and 2-4 years was defined by the eruption of M1, M2 and M3 respectively in sheep. Using this methodology - given that goat molars on average erupt later - would produce incorrect age estimates. Further studies are needed on 

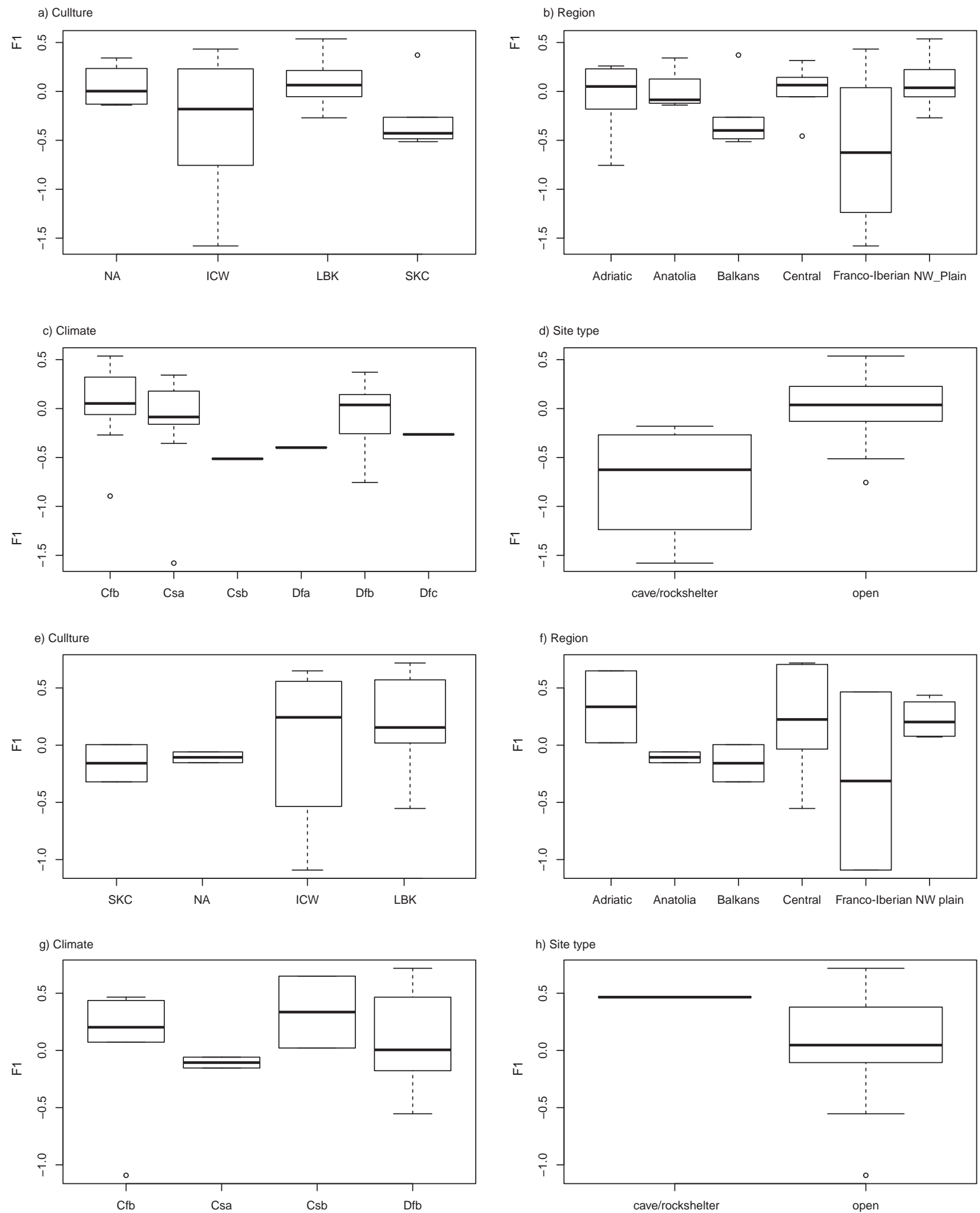

Figure 3. Boxplots for F1 sheep and goat F1 coordinates: (a) Sheep F1 Region; (b) Sheep F1 Culture; (c) Sheep F1 Site type; (d) Sheep F1 Climate; (e) Goat F1 Region; (f) Goat F1 Culture; (g) Goat F1 Site type; (h) Goat F1 Climate.

Table 2. The results of the ANOSIM (R statistic/ probability) test on the mean CA F1 and F2 coordinates for sheep and goats from each site using cultural group, climate, site type and region as grouping factors.

\begin{tabular}{ccccc}
\hline & Culture & Climate & Site type & \multicolumn{1}{c}{ Region } \\
\hline Goat F1 & $-0.04 / 0.6$ & $-0.07 / 0.7$ & $-0.05 / 0.4$ & $0.02 / 0.4$ \\
Goat F2 & $-0.02 / 0.5$ & $-0.07 / 0.7$ & $0.4 / 0.1$ & $0.02 / 0.4$ \\
Sheep F1 & $0.2 / 0.005^{*}$ & $2.9 \mathrm{e}-5 / 0.4$ & $0.4 / 0.008^{*}$ & $0.14 / 0.03^{*}$ \\
Sheep F2 & $0.06 / 0.2$ & $0.2 / 0.3$ & $0.02 / 0.3$ & $0.07 / 0.1$ \\
\hline
\end{tabular}

*indicates statistical significance. large cohorts of goats to extend and establish goat specific age determination methodologies.

Other factors, such as human error and age of specimen, can also affect species identification. Confidence and rate of attribution to species can differ between archaeozoologists, between samples and within samples. This and the effect of age on the visibility of different criteria can led to misidentified sheep as 
goat and vice a versa (Orton pers. comm.). In addition, sheep and goats from different geographical regions may have slightly different morphological characteristics. Although, this has not been the subject to scientific study, it is a common dissuasive point amongst archaeozoologists. Consequently, future studies are needed to assess whether there are differences in morphological characteristics between regions (i.e. Middle East verses Europe), and its impact on species identification as well as the effect on age on criteria and determinations. This could be done in conjunction with biomolecular approaches to determine sheep and goat where research funds are sufficient for analytical costs (Pilaar-Birch et al. 2018; Prendergast et al. 2018).

\section{Sheep}

Our results suggest that there were differences in slaughter practices between cultural groups and regions. In general, the southern Europe and northwestern Mediterranean SKC and ICW sites are associated with age classes 6-12 months and to a lesser extent 2-6 months in comparison to LBK sites where sites are more closely associated with adult age classes.

Infant animals are a rich source of fat as well as meat, however, the age of slaughter is dependent on husbandry practices (i.e. slaughter of young to increase dairy production), the needs of the society and their culinary tastes. The cheese and yoghurt from sheep and goat milk is particularly economically important for modern Mediterranean and Balkan countries where $55 \%$ of the world's sheep milk is currently produced (Boyazoglu and Morand-Fehr 2001). Ethnographic examples have shown that lambs and kids can be removed without affecting the flow of milk (Halstead 1998) however sheep do require lambs to stimulate milk ejection from the aveoli to the cistern at the beginning of the lactation period (Balasse 2003). If sheep milk is being exploited, the weaning age varies between 2-6 months and is dependent on the intensity of the production and whether milk or lamb meat is the focus of the operation (Hadjikoumis 2017). The traditional Mediterranean management, where sheep milk is highly prised, the lambs are separated and weaned at early so that full milking can take place for five months (Halstead 1998; Hadjikoumis 2017).

Previous multi-proxy analysis of organic residues from ceramics and mortality data analysis has demonstrated that milking was practised from the beginning of the Neolithic in the north-western Mediterranean (Debono Spiteri et al. 2016). Furthermore, cave sites may have played an important role in milk production and were used as a part of a pastoral systems where animals were brought to cave sites for surrounding pasture resources and temporary birthing stations. Transhumant practices have long been a tradition in the Balkans and Greece. For example, the Vlach communities, who ranged from Greece to former Czechoslovakia and built special housing on summer pastures for milking ewes and processing milk (Ryder 1999). Previous analysis of caprines from cave and open sites in Southern France has shown that sites were used complementary with cave sites acting as seasonal birthing stations (Bréhard, Beeching, and Vigne 2010; Helmer and Vigne 2004; Vigne and Helmer 1999).

If we accept that the slaughter focused of animals aged 2-6 months is associated with dairying and slaughter of older lambs (6-12 months) is the result of a staggered slaughter throughout the year to provide meat (Helmer, Gourichon, and Vila 2007; Vigne, Carrère, and Guilaine 2017; Hadjikoumis 2017; Halstead 1998). Then our results from sites in the Balkans and Mediterranean seaboard would suggest that sheep were used for dairying as well as for meat in these regions, which would correlate with previous analysis by Debono Spiteri et al. (2016). We do not suggest large-scale sheep milking that is seen at present, as it is labour intensive and for good milk returns the evolution of specialised breeds is required. However, as sheep's milk is very rich in fat and excellent for cheese making it is not unreasonable to postulate that early Neolithic farmers exploited this resource seasonally on a small scale within a mixed pastoral economy. In comparison, stockherders of the LBK appear to have slaughtered animals as young adults and adults supporting previous analysis that has shown cattle as the primary dairy animal (Gillis et al. 2017) and sheep were only used as a source of meat as suggested by Marciniak (2013). This could also explain why Trasano and La Draga are also associated with adult age classes as at these sites cattle appear to have been the primary dairy animal (Gillis et al. 2016).

\section{Goats}

Previous ethnographic studies of Near Eastern societies have shown that goats are generally managed for household production (Redding 1981). Vigne and Helmer (1999) pointed out that goats were much more frequently used for milk in the early Neolithic of the Mediterranean area than sheep, and explained this difference by the fact that it is easier to milk goats than sheep. Greenfield and Arnold (2015) have also suggested that goats were managed for milk from the beginning of the Neolithic in the Balkans. Female goats, does can be easily milked without need of the presence of their infants and their milk is more digestible than cow's milk (Haenlein 2007, 2004). Does have long productive lives as well as long lactation period (198-285 days, (Gillis 2012)). Consequently, adult age classes particularly those greater than 4 years could support a dairy hypothesis. Young slaughter (0-6 months) could also be a reflection of dairying 
with infants being removed early in the lactation period to increase milk for human consumption. However, in a recent ethnographic study of Cypriot herders, kids were reported to be slaughtered later than lambs due to the faster growth rate of lambs and the richer milk of ewes (Hadjikoumis 2017). Furthermore, bucks were commonly slaughter around two years old in comparison to rams as it was herders believed that younger bucks produced bigger kids and had greater fertility success. Therefore a typical goat mortality profile may have peaks for kid slaughter in age class 2-6 months, bucks in age classes between 1-3 years and does in age classes $>4$ years.

The interpretation of the results is hampered by the sample sizes, as well as other methodological issues. Two of the sites, Polgár-Piócási-Dülő (PIO) and Füzseabony (FUZ) have large samples sizes $(>50)$ and if omitted the mean sample size is 16.5 , which makes it difficult to discern specific management strategies for all sites. However, for PIO, FUZ and La Draga (LAD), it is possible to distinguish different management strategies. LAD plots close to age class 1-2 years while FUZ lies between age classes 6-12 months and 2-4/4-6 years while POI is associated with the latter classes. Therefore we propose that at FUZ mixed strategies of both meat and milk were probably practised, whereas at PIO goats may have been used primary for milk. While the goat profiles at LAD may have been dominated with male goats, possible suggesting goats were slaughtered for meat. The lack of significance between region, climate and culture may be the result of low samples sizes, which is probably a direct reflection of small goats herds.

\section{Conclusions}

Sheep and goats are similar osteologically but are currently exploited differently as a result of their individual productive capacities and environmental tolerances. The results from the analysis of species specific mortality data from early Neolithic contexts here suggest that sheep were managed differently between regions and cultural groups. In southern European contexts primarily young animals were slaughtered, which may reflect dairy husbandry as well as a cultural preference for young tender meat. In northern regions, sheep and goat are used as a source of meat rather than milk. This change in management strategies may be related to cultural preferences and practices as well as the geography and hydrology of the region being ideal for cattle. For goats overall, due to small samples it was not clear whether they were managed for specific purposes, such as milk production, nor whether there were regional/cultural differences. This may be related to the fact that only small numbers of goats were kept.
To further investigate the evolution and development of sheep and goat husbandry, future analysis is required to further increase the number of species specific mortality datasets and extend this study to other periods of the Neolithic. Here we have taken a large corpus of species specific data from several regions unlike previous analyses, which have focused on one region or site (Greenfield and Arnold 2015). There are a number of methodological issues that need to be resolved, such species specific age-at-death determination methods, as well as the security of the correct identifications, and whether the age distribution can have an impact on these determinations. However, as an initial examination it offers a tantalising glimpse into early goat and sheep husbandry practices and how the first farmers of Europe adapted these domesticates to new environments and moulded husbandry practices in response to cultural tastes and preferences.

\section{Acknowledgements}

The authors would like to thank the two anonymous reviewers, whose comments greatly improved this article. RG's research into ICW caprines was carried out during a $\mathrm{PhD}$ funded by LeCHE (Marie Curie Initial Training Networks (FP7-ITN-215362-2)) and for LBK caprines during a postdoc funded by the European Research Council NeoMilk project awarded to Prof. R.P. Evershed (FP7-IDEASERC/324202) hosted by MNHN, Paris. The paper was written during a postdoc hosted by the Graduate School, CAU, Kiel. RG would like to thank to those who allowed access to material during these projects: Dr Rose-Marie Arbogast (UMR7044, Université de Strasbourg, France); Prof Jean Guilaine and Isabelle Carrère (CNRS-UMR 5608, Université Le Mirail, France); Dr Giovanni Radi (Università di Pisa, Italy); Dr Maria Saña Segui (Universitat autònoma de Barcelona, Spain); Dr Andrea Zeeb-Lanz (Lansesarchäologie Speyer, Germany); Drs Ivana Vostrovská and Eliška Kazdová (Masaryk University, Czech Republic); Prof. Erich Pucher (Museum of Natural History, Austria); Dr László Domboróczki' Sándor Tanyi and Kristóf Rácz (István Dobó Castle Museum, Hungary); Prof. Pál Raczky, Dr Alexandra Anders and Dr Péter Csippán (Institute of Archaeological Sciences, Hungary); Dr. Henriette Obermaier (Staatssammlung für Anthropologie und Paläoanatomie München); Dr Joachim Pechtl (kelten römer museum Manching, Germany); Prof. Arkadiusz Marciniak (Instytut Archeologii UAM, Poland). She would also like to thank Prof Mark Thomas (UCL, UK) and Dr Pascale Gerbault (University of Westminster, UK) for statistical advice. JSG post doc was funded by the European Research Council project EUROFARM (FP/ 20072013; ERC Grant Agreement no. 313716), led by MVL and hosted by UCL.

\section{Disclosure Statement}

No potential conflict of interest was reported by the authors.

\section{Funding}

This work was supported by Marie Sklodowska Curie Actions [grant number FP7-ITN-215362-2]; ERC [grant 
number FP/20072013; ERC Grant Agreement no. 313716]; ERC [grant number FP/20072013; ERC Grant Agreement no. 313716]; ERC [grant number FP7-IDEAS-ERC/324202].

\section{Notes on contributors}

Rosalind E. Gillis is a post-doc alumni of the Graduate School, Christian-Albrechts-Universität zu Kiel (Germany) and will start a fellowship at the Interdisciplinary Center for Archaeology and Evolution of Human Behaviour (Faro, Portugal). Her research focuses on investigating animal husbandry practices of the early Neolithic Europe using age-atdeath from animal teeth in combination with stable isotopic analysis. She is widely published in a number of international journals and special volumes.

Jane S. Gaastra did her BA in anthropology at the University of Pittsburgh, Mphil and PhD in Archaeology at University of Cambridge. At the time of the conference and of the writing of the article(s) she was post-doctoral research associate on ERC project EURO Farm at University College London (in the Institute of Archaeology). She does research on prehistoric and protohistoric zooarchaeology of Europe, the Near East and Africa.

Dr Marc Vander Linden works on European Neolithic, with particular interest in the spread of early farming, population dynamics and human-environment interactions. He has conducted fieldwork in Belgium, Syria, the UK, and more recently in Bosnia and Herzegovina and Montenegro as part of a five-year project on the introduction of early farming in the western Balkans.

Dr Jean-Denis Vigne is a Director of Research of the CNRS. $\mathrm{He}$ is a field archaeologist and an archaeozoologist. His research concerned the late prehistoric societies and their natural, technical and symbolic relationships with the animal biodiversity, with a special focus on islands. He worked on the southwestern Europe, the Middle East (especially Cyprus), central Asia and North China. He produced original results about the evolution of the exploitation of animal resources from the Mesolithic to the Bronze Age, including animal domestication and the dawn of milk exploitation. $\mathrm{He}$ also contributed to the dynamics of biodiversity under human pressures. He was the director of the laboratory of Archaeozoology and archaeobotany of the French National Natural History Museum (2002-2012), and leaded several international projects or networks. He is now the Director for research, expertise, valorization and teaching of the Museum. He wrote or edited 19 books and published more than 400 articles.

\section{ORCID}

Rosalind E. Gillis (D) http://orcid.org/0000-0002-2370-7311 Jane S. Gaastra (D) http://orcid.org/0000-0003-4782-9337 Marc Vander Linden (D) http://orcid.org/0000-0002-01207754

Jean-Denis Vigne (D) http://orcid.org/0000-0002-7367-7552

\section{References}

Arbuckle, B. S. 2008. "Caprine Exploitation at Erbaba Höyük: A Pottery Neolithic Village in Central Anatolia." In Archaeozoology of Southwestern Asia and Adjacent Areas VIII, edited by L. Gourichon, and E. Vila, 345365. Paris: Travaux de la Maison de l'Orient.
Arbuckle, B. S., S. W. Kansa, E. Kansa, D. Orton, C. Cakirlar, L. Gourichon, L. Atici, et al. 2014. "Data Sharing Reveals Complexity in the Westward Spread of Domestic Animals Across Neolithic Turkey." PLoS One 9 (6): e99845. doi:10. 1371/journal.pone.0099845.

Balasse, M. 2003. "Keeping the Young Alive to Stimulate Milk Production? Differences between Cattle and Small Stock." Anthropozoologica 37: 271-282.

Balasse, M., and S. H. Ambrose. 2005. "Distinguishing Sheep and Goats Using Dental Morphology and Stable Carbon Isotopes in C 4 Grassland Environments." Journal of Archaeological Science 32 (5): 691-702.

Benzécri, J.-P. 1973. L'analyse des Données. Paris: Dunod.

Boessneck, J., H.-H. Müller, and M. Teichert. 1964. "Osteologiche Unterscheidungsmerkmale Zwischen Schaf (Ovis Aries Linné) und Ziege (Capra Hircus Linné)." Kühn-Archiv 78: 1-29.

Boyazoglu, J., and P. Morand-Fehr. 2001. "Mediterranean Dairy Sheep and Goat Products and Their Quality: A Critical Review." Small Ruminant Research 40: 1-11.

Bréhard, Stéphanie, Alain Beeching, and Jean-Denis Vigne. 2010. "Shepherds, Cowherds and Site Function on Middle Neolithic Sites of the Rhône Valley: An Archaeozoological Approach to the Organization of Territories and Societies." Journal of Anthropological Archaeology 29 (2): 179-188. doi:10.1016/j.jaa.2010.02. 001.

Brighton, D., K. Dobney, and John Chapman. 2010. "The Faunal Remains." In Lowland Settlement in North East Hungary: Excavations at the Neolithic Settlement Site of Polgár-10, edited by John Chapman, M. Gillings, R. Shiel, B. Gaydarksa, and C. Bond, 287-301. Oxford: Archaeopress.

Bullock, D., and D. J. Rackham. 1982. "Epiphysial Fusion and Tooth Eruption of Feral Goats From Moffatdale, Dumfries and Galloway, Scotland." In Ageing and Sexing Animal Bones from Archaeological Sites, edited by B. Wilson, C. Grigson, and S. Payne, 73-80. Oxford.

Çakirlar, Canan. 2012. "Neolithic Dairy Technology at the European-Anatolian Frontier: Implications of Archaeozoological Evidence From Ulucak Höyük, İzmir, Turkey, ca. 7000-5700 cal. BC.” Anthropozoologica 47 (2): 77-98. doi:10.5252/az2012n2a6.

Debono Spiteri, C., Rosalind E. Gillis, M. Roffet-Salque, L. Castells Navarro, J. Guilaine, C. Manen, I. M. Muntoni, et al. 2016. "Regional Asynchronicity in Dairy Production and Processing in Early Farming Communities of the Northern Mediterranean.” PNAS USA 113 (48): 1359413599. doi:10.1073/pnas.1607810113.

Deniz, E., and S. Payne. 1982. "Eruption and Wear in the Mandibular Dentition as A Guide to Ageing in Turkish Angora Goats." In Ageing and Sexing Animal Bones from Archaeological Sites, edited by B. Wilson, C. Grigson, and S. Payne, 155-205. Oxford: BAR.

Ducos, Pierre. 1968. "Chapitre 2: Èlaboration de Statistiques." In L'origine des Animaux Domestiques en Palestine, 6-15. Bordeaux: Institue de Préhistorie de l'Université.

El Susi, G. 2000. "Determinarea Resturilor Faunistice DintrO Locuință Neolitică Timpurie de la Seuşa - "La Cărarea Morii" (jud. Alba)." Banatica 15 (1): 49-57.

Ewbank, J. M., D. W. Phillipson, R. D. Whitehouse, and E. S. Higgs. 1964. "Notes: Sheep in the Iron Age: A Method of Study." Proceedings of the Prehisotric Society 30: 423-426.

Feeser, I., W. Dörfler, M. Czymzik, and S. Dreibrodt. 2016. "A mid-Holocene Annually Laminated Sediment 
Sequence From Lake Woserin: The Role of Climate and Environmental Change for Cultural Development During the Neolithic in Northern Germany." The Holocene 26 (6): 947-963.

Fiorentino, G., M. Caldara, V. De Santis, C. D’Oronzo, I. M. Mutoni, O. Simone, M. Primavera, and F. Radina. 2013. "Climate Changes and Human-Environment Interactions in the Apulia Region of Southeastern Italy During the Neolithic Period." The Holocene 23 (9): 1297-1316.

Gaastra, J. S. 2016. “The Quadratic Crown Height Method and Bovidae: Ageing Sheep (Ovis Aries), Goats (Capra Hircus) and Cattle (Bos Taurus)." Journal of Archaeological Science: Reports 10: 172-190. doi:10.1016/ j.jasrep.2016.09.022.

Gerbault, Pascale, Rosalind E. Gillis, Jean-Denis Vigne, Anne Tresset, Stéphanie Bréhard, and Mark G. Thomas. 2016. "Statistically Robust Representation and Comparison of Mortality Profiles in Archaeozoology." Journal of Archaeological Science 71: 24-32. doi:10.1016/j.jas.2016. 05.001.

Gillis, Rosalind E. 2012. "Osteological and Isotopic contributions to the Study of Dairy Husbandry During the European Neolithic." PhD, Département Ecologie et Gestion de la Biodiversité, Université de Paris I (2).

Gillis, R. E., I. Carrère, M. Saña Seguí, G. Radi, and J.-D. Vigne. 2016. "Neonatal Mortality, Young Calf Slaughter and Milk Production during the Early Neolithic of North Western Mediterranean.” International Journal of Osteoarchaeology 26 (2): 303-313.

Gillis, Rosalind E., Louis Chaix, and Jean-Denis Vigne. 2011. "An Assessment of Morphological Criteria for Discriminating Sheep and Goat Mandibles on A Large Prehistoric Archaeological Assemblage (Kerma, Sudan)." Journal of Archaeological Science 38 (9): 2324-2339. doi:10.1016/j.jas.2011.04.012.

Gillis, Rosalind E., Lenka Kovačiková, Stéphanie Bréhard, Emilie Guthmann, Ivana Vostrovská, Hana Nohálová, Rose-Marie Arbogast, et al. 2017. "The Evolution of Dual Meat and Milk Cattle Husbandry in Linearbandkeramik Societies." Proceedings of the Royal Society B: Biological Sciences 284 (1860): 20170905.

Greenfield, Haskel J., and Elizabeth R. Arnold. 2015. “"Go (A)T Milk?' New Perspectives on the Zooarchaeological Evidence for the Earliest Intensification of Dairying in South Eastern Europe.” World Archaeology 47 (5): 792818. doi:10.1080/00438243.2015.1029076.

Greenfield, Haskel J., and T. L. Jongsma Greenfield. 2014. "Subsistence and Settlement in the Early Neolithic of Temperate SE Europe: A View From Blagotin, Serbia." Archaeologia Bulgarica 18 (1): 1-33.

Hadjikoumis, Angelos. 2017. "Age-at-death in Traditional Cypriot Sheep and Goat Husbandry: Implications for Zooarchaeology." In Economic Zooarchaeology: Studies in Hunting, Herding and Early Agriculture, edited by P. Rowley-Conwy, D. Serjeantson, and P. Halstead, 126134. Oxford: Oxbow.

Haenlein, G. F. W. 2001. "Past, Present, and Future Perspectives of Small Ruminant Dairy Research." Journal of Dairy Science 84: 2097-2115.

Haenlein, G. F. W. 2004. "Goat Milk in Human Nutrition." Small Ruminant Research 51 (2): 155-163. doi:10.1016/j. smallrumres.2003.08.010.

Haenlein, G. F. W. 2007. "About the Evolution of Goat and Sheep Milk Production." Small Ruminant Research 68 (12): 3-6. doi:10.1016/j.smallrumres.2006.09.021.
Halstead, P. 1998. "Mortality Models and Milking: Problems of Uniformitarianism, Optimality and Equifinality Reconsidered." Anthropozoologica 27: 3-20.

Halstead, P., P. Collins, and V. Isaakidou. 2002. "Sorting the Sheep from the Goats: Morphological Distinctions Between the Mandibles and Mandibular Teeth of AdultOvis and Capra." Journal of Archaeological Science 29 (5): 545-553. doi:10.1006/jasc.2001.0777.

Helmer, D. 2000. "Discrimination des Genres Ovis et Capra à L'aide des Prémolaires Inférieures 3 et 4 et Interprétation des âges D'abattage; L'exemple de Dikili Tash (Grèce)." Anthropozoologica 31: 29-38.

Helmer, D., L. Gourichon, and J.-D. Vigne. 2005. "L'élevage des caprinés néolithiques dans le sud-est de la France: saisonnalité des abattages, relations entre grottes-bergeries et sites de plein air." Anthropozoologica 40 (1): 167-189.

Helmer, Daniel, L. Gourichon, and Emmanuelle Vila. 2007. "The Development of the Exploitation of Products From Capra and Ovis (Meat, Milk and Fleece) From the PPNB to the Early Bronze in the Northern Near East (8700 to 2000 BC cal.)." Anthropozoologica 41 (2): 41-69.

Helmer, D., and J. D. Vigne. 2004. "La gestion des cheptels de caprinés au Néolithique dans le Midi de la France." Approches Fonctionnelles en Préhistoire, Actes du XXVe Congrès Préhistorique de France Nanterre, 24-26 novembre 2000.

Jones, G. 2006. "Tooth Eruption and Wear Observed in Live Sheep from Butser Hill, the Cotswold Farm Park and Five Farms in the Pentland Hills, UK." In Recent Advances in Ageing and Sexing Animal Bones, edited by D. Ruscillo, 155-178. Oxford: Oxbow.

Kahle, D., and H. Wickham. 2013. "Ggmap: Spatial Visualization with ggplot2.” The R Journal 5 (1): 144-161.

Lüning, J. 2000. Steinzeitliche Bauern in Deutschland. Die Landwirtschaft im Neolithikum. Bonn: Habelt.

Manning, K., B. Stopp, S. Colledge, S. S. Downey, J. Connolly, K. Dobney, and S. Shennan. 2013. "Animal Exploitation in the Early Neolithic of the Balkans and Central Europe." In The Origins and Spread of Domestic Animals in Southwest Asia and Europe, edited by S. Colledge, J. Conolly, K. Dobney, K. Manning, and S. Shennan, 237-252. California: Left coast press.

Marciniak, A. 2013. "Origin of Stock-Keeping and the Spread of Animal Exploitation Strategies in the Early and Middle Neolithic of the North European Plain." In The Origins and Spread of Domestic Animals in Southwest Asia and Europe, edited by S. Colledge, J. Conolly, K. Dobney, K. Manning, and S. Shennan, 221236. California: Left Coast Press.

Mellado, M., L. Olivares, W. Pittroff, H. Díaz, R. López, and J. A. Villarreal. 2007. "Oral Morphology and Dietary Choices of Goats on Rangeland." Small Ruminant Research 71 (1-3): 194-199. doi:10.1016/j.smallrumres. 2006.06.005.

Nenadic, O., and M. Greenacre. 2007. "Correspondence Analysis in R, with Two- and Three-Dimensional Graphics: The ca Package." Journal of Statisical Software 20 (3): 1-13.

Oksanen, Jari, F. Guillaume Blanchet, Michael Friendly, Roeland Kindt, Pierre Legendre, Dan McGlinn, Peter R. Minchin, et al. 2017. $R$ Package Version 2.4-5. Vegan: Community Ecology Package.

Orton, David, Jane Gaastra, and Marc Vander Linden. 2016. "Between the Danube and the Deep Blue Sea: Zooarchaeological Meta-Analysis Reveals Variability in the Spread and Development of Neolithic Farming Across the Western Balkans.” Open Quaternary 2. 
Payne, Sebastian. 1973. "Kill-off Patterns in Sheep and Goats: The Mandibles from Aşvan Kale.” Anatolian Studies 23 (281-303).

Payne, S. 1987. "Reference codes for wear states in the mandibular cheek teeth of sheep and goats." Journal of Archaeological Sciences 14 (6): 609-614.

Peel, M. C., B. L. Finlayson, and T. A. McMahon. 2007. "Updated World map of the Köppen-Geiger Climate Classification." Hydrology and Earth System Sciences Discussions, European Geosciences Union 11 (5): 1633-1644.

Peters, J., D. Helmer, A. Von Den Driesch, and M. Saña Segui. 1999. "Early Animal Husbandry in the Northern Levant." Paléorient 25 (2): 27-48.

Pilaar-Birch, Suzanne E., A. Scheu, M. Buckley, and C. Cakirlar. 2019. "Combined Osteomorphological, Isotopic, aDNA, and ZooMS Analyses of Sheep and Goat Remains from Neolithic Ulucak, Turkey." Archaeological and Anthropological Sciences.

Poplin, F. 1979. "Origine du Mouflon de Corse Dans une Nouvelle Perspective Paléontologique: par Marronnage.” Annales de Génétique et de Sélection aNimale 11 (2): 133-143.

Prendergast, Mary E., Anneke Janzen, Michael Buckley, and Katherine M. Grillo. 2018. "Sorting the Sheep From the Goats in the Pastoral Neolithic: Morphological and Biomolecular Approaches at Luxmanda, Tanzania." Archaeological and Anthropological Sciences.

Redding, R. W. 1981. "Decision Making in Subsistence Herding of Sheep and Goats of the Middle East." PhD, University of Michigan.

Rowley-Conwy, P. 1997. "The Animal Bones From Arene Candide. Final Report." In Arene Candide: Functional and Environmental Assessment of the Holocene Sequence, edited by R. Maggi, 153-277. Rome: Memorie dell'Istituto Italiano di Paleontologia Umana.

Rowley-Conwy, P. A., L. Gourichon, D. Helmer, and J.-D. Vigne. 2013. "Early Domestic Animals in Italy, Istria, the Tyrrhenian Islands, and Southern France." In The Origins and Spread of Domestic Animals in Southwest Asia and Europe, edited by S. Colledge, J. Conolly, K. Dobney, K. Manning, and S. Shennan, 161-194. Left Coast Press.

Ryder, M. L. 1999. "Did Vlach Shepherds Spread SheepMilking Customs through South-East Europe?" In Transhumant Pastoralism in Southern Europe: Recent Perspectives from Archaeology, History and Ethnology, edited by L. Bartosiewicz, and H. J. Greenfield, 189-196. Budapest: Archaeolingua.

Silver, A. 1963. "The Ageing of Domesticated Animals." In Science in Archaeology: A Comprehensive Survey of
Progress and Research, edited by D. Brothwell, and E. Higgs, 250-268. London: W.B. Saunders.

Statisticat, LLC. 2016. "LaplacesDemon: Complete Environment for Bayesian Inference.” Bayesian-Inference.com.

Team, RStudio. 2016. RStudio: Integrated Development for $R$. http://www.rstudio.com/.

Uerpmann, H.-P. 1987. "The Origin and Relations of Neolithic Sheep and Goats in the Western Mediterranean." In Premières Communautés Paysannes en Mediterranée Occidentale, edited by J. Guilaine, J. Courtin, J.-L. Roudil, and J.-L. Vernet, 176-179. Paris.

Venables, W. N., and B. D. Ripley. 2002. Modern Applied Statistics with S. 4th ed. New York: Springer.

Vigne, J.-D., I. Carrère, F. Briois, and J. Guilaine. 2011. "The Early Process of the Mammal Domestication in the Near East: New Evidence From the Pre-Neolithic and PrePottery Neolithic in Cyprus." Current Anthropology 52 (4): 255-271.

Vigne, J.-D., I. Carrère, and J. Guilaine. 2017. "Instability and co-Development of the Exploitation of Early Domestic Sheep and Goats: the Example of Shillourokambos (Cyprus, Pre-Pottery Neolithic, 10,400-9,000 cal BP).” In Archaeozoology of the Near East 9 (Proceedings of the 9th ASWA Conference, Al Ain, 2008), edited by M. Mashkour, and M. Beech, 10-22. Oxford: Oxbow Books.

Vigne, J. D., and D. Helmer. 1999. "Nouvelles Analyses sur les Débuts de L'élevage Dans le Centre et L'ouest Méditerranéens." In Le Néolithique du Nord-Ouest Méditerranéen. Actes du 24ème Congrès. Préhistorique de France, edited by J. Vaquer, 129-146.

Vigne, J. D., and D. Helmer. 2007. "Was Milk A"Secondary Product" in the Old World Neolithisation Process? Its Role in the Domestication of Cattle, Sheep and Goats." Anthropozoologica 42 (2): 9-40.

Weinreb, M., and Y. Sharav. 1964. "Tooth Development in Sheep." American Journal of Veterinary Research 25.

Whittle, A. W. R., A. R. Anders, A. Bentley, P. Bickle, L. Cramp, L. Domboróczki, L. Fibiger, et al. 2013. "3. Hungary." In The First Farmers of Central Europe: Diversity in LBK Lifeways, edited by A. W. R. Whittle, and P. Bickle. Oxford: Oxbow Books.

Wickham, H. 2009. Ggplot2: Elegant Graphics for Data Analysis. New York: Springer.

Zeder, Melinda A. 1999. "Animal Domestication in the Zagros: A Review of Past and Current Research." Paléorient 25 (11-25).

Zeder, Melinda A., and Suzanne E. Pilaar. 2010. “Assessing the Reliability of Criteria Used to Identify Mandibles and Mandibular Teeth in Sheep, Ovis, and Goats, Capra." Journal of Archaeological Science 37 (2): 225242. doi:10.1016/j.jas.2009.10.002. 